\title{
Prevalence of third molar impaction in orthodontic patients treated nonextraction and with extraction of 4 premolars
}

\author{
Tae-Woo Kim, DDS, MSD, PhD, ${ }^{a}$ Jon Årtun, DDS, Dr Odont, ${ }^{\mathrm{b}}$ Faraj Behbehani, DDS, MS, ${ }^{\mathrm{c}}$ and \\ Flavia Artese, DDS, MSc ${ }^{\text {d }}$ \\ Seoul, Korea; Safat and Kuwait City, Kuwait; Rio de Janeiro, Brazil
}

\begin{abstract}
The purposes of this study were to confirm that premolar extraction treatment is associated with mesial movement of the molars concomitant with an increase in the eruption space for the third molars and to test the hypothesis that such treatment reduces the frequency of third molar impaction. Lateral cephalograms, panoramic or periapical radiographs, and study models made before (T1) and after (T2) treatment and a minimum of 10 years postretention (T3) of 157 patients were selected from the postretention sample at the Department of Orthodontics of the University of Washington, Seattle. Treatment for 105 patients included the extraction of 4 premolars; the other 53 were treated nonextraction. These patients represented all the extraction and nonextraction patients in the sample who had at least 1 third molar at T1 or T2 and who showed evidence of full eruption or closure of the root apex at T2 or T3. Student $t$ tests showed higher scores for third molar impaction $(P<.01)$, less mesial movement of the molars from T1 to T2 $(P<.01)$, and smaller retromolar space at T2 $(P<.001)$ in both arches of the nonex patients than in the ex patients. Similarly, molar movement was more mesial from T1 to T2 in the maxilla $(P<.01)$ and in the mandible $(P<.05)$, and the retromolar space was larger in both arches $(P<.001)$ of the patients with eruption than in those with impaction of the third molars. Our results suggest that premolar extraction therapy reduces the frequency of third molar impaction because of increased eruption space concomitant with mesial movement of the molars during space closure. (Am J Orthod Dentofacial Orthop 2003;123:138-45)
\end{abstract}

$\mathbf{T}$ The impaction rate is higher for the third molars than for any other teeth in modern populations. $^{1-3}$ One explanation could be that the retromolar space frequently is inadequate. ${ }^{4-7}$ If the remodeling resorption at the anterior aspect of the mandibular ramus $^{4-7}$ is limited, the eruption of the mandibular third molars might be blocked. Similarly, lack of compensatory periosteal apposition at the posterior outline of the maxillary tuberosities could prevent eruption of the maxillary third molars. The eruption space for the mandibular third molars is also affected by the direction the teeth erupt during the functional phase of eruption. The more anteri-

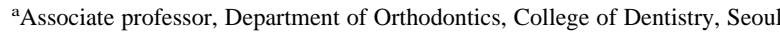
National University, Seoul, Korea.

${ }^{\mathrm{b}}$ Professor, Department of Developmental and Preventive Sciences, Kuwait University, Safat, Kuwait.

cOrthodontist, Ministry of Health, Kuwait City, Kuwait.

${ }^{\mathrm{d}}$ Visiting professor, Department of Orthodontics, School of Dentistry, Federal University of Rio de Janeiro, Rio de Janeiro, Brazil.

Reprint requests to: Dr Jon Årtun, Department of Developmental and Preventive Sciences, Kuwait University Faculty of Dentistry, P. O. Box 24923, Safat 13110 Kuwait; e-mail, artun@hsc.kuniv.edu.kw.

Accepted for publication, June 2002.

Copyright (C) 2003 by the American Association of Orthodontists.

$0889-5406 / 2003 / \$ 30.00+0$

doi: $10.1067 / \bmod .2003 .13$
}

orly the posterior teeth erupt, the more the retromolar space will increase. ${ }^{4,5}$

Skull materials indicate that third molar impaction was relatively infrequent in primitive populations. ${ }^{6,8,9}$ This has been attributed to mesial drift of the posterior teeth because of excessive interproximal attrition, thereby increasing the retromolar space. Similarly, third molar impaction is rarely observed after second molar extraction. ${ }^{10,11}$ These studies suggest that mesial movement of the molars and a concomitant increase in eruption space are likely to reduce the frequency of third molar impaction.

It is well established that extraction therapy is associated with mesial movement of the mandibular molars ${ }^{12-14}$ and the increase in retromolar space. ${ }^{12-15}$ However, the effect of those changes on the frequency of mandibular third molar impaction is unclear. ${ }^{12,13,15-20}$ Some researchers have found that nonextraction therapy is associated with a significant increase in the frequency of third molar impaction $^{15,17-19}$ and a significant reduction in the frequency of third molar eruption, ${ }^{12,16}$ while others have found only small differences between samples treated with and without extraction. ${ }^{13,20}$ Information on the effect 

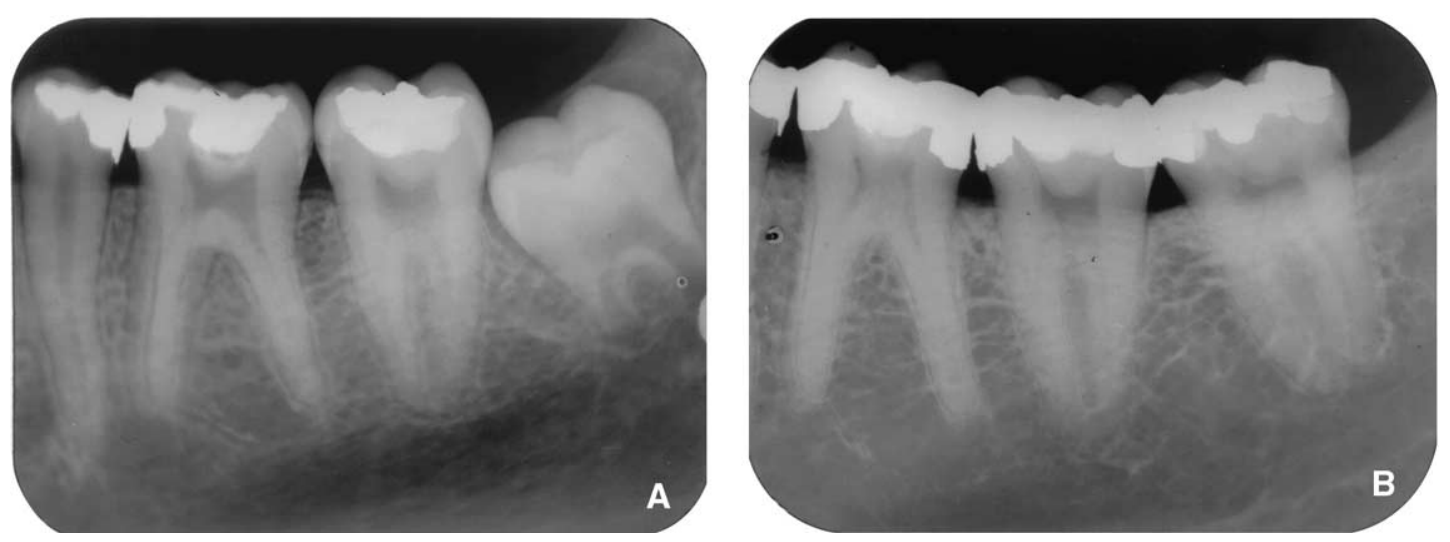

Fig 1. Periapical radiographs made at $\mathbf{A}, 15$ years 9 months, and $\mathbf{B}, 29$ years 10 months of a patient who had received orthodontic treatment with extraction of 4 first premolars. Note eruption of mandibular third molars during final stage of root formation despite apparent impaction at age 15 years 9 months.

of extraction therapy on maxillary third molar impaction is very limited.

The samples in several of the above studies were small $^{12,15-17}$ and might not have represented the general population. Other potential problems include differences in the ages of the subjects and in the criteria used to diagnose impaction. Case studies suggest a potential for third molar eruption during the final stages of root formation, despite apparent signs of development of impaction (Fig 1). The average age at third molar emergence ranges from 17 to 21 years, but the roots are not fully formed until 18 to 25 years of age. ${ }^{21,22}$ Accordingly, third molar impaction could have been overdiagnosed in studies examining subjects less than 20 years old. ${ }^{12,16,18-20}$ Also, practitioners who believe that the mesial pressure of erupting third molars is a significant factor for relapse of incisor alignment are likely to recommend early removal. Scoring previous surgical removal of mandibular third molars as impaction ${ }^{16,18}$ could imply a systematic overdiagnosis of impaction, particularly in nonextraction cases, thereby biasing the results.

The purposes of this study were to confirm that premolar extraction treatment is associated with mesial movement of the molars concomitant with an increase in the eruption space for the third molars and to test the hypothesis that such treatment reduces the frequency of third molar impaction.

\section{MATERIAL AND METHODS}

Lateral cephalograms, panoramic or periapical radiographs, and study models made before (T1) and after (T2) treatment and a minimum of 10 years postretention (T3) of all patients without dentofacial deformities, severe facial asymmetries, or missing teeth other than 4 premolars, and who had been treated nonextraction $(\mathrm{n}=242)$ or with the extraction of 4 premolars $(n=315)$ by faculty members or graduate students in the Department of Orthodontics at the University of Washington, Seattle, were examined. A total of 389 patients had radiographic evidence of at least 1 third molar at $\mathrm{T} 1$ or $\mathrm{T} 2$. The patients whose developing third molars had been removed before evidence of apical root closure or whose radiographs did not allow identification of the apices of the remaining third molars were excluded. The final sample consisted of 157 patients. A total of 51 were treated nonextraction (nonex), of whom 41 could be evaluated in the maxilla and 38 in the mandible, and 106 were treated with extraction of 4 premolars (ex), of whom 91 could be scored in the maxilla and 96 in the mandible. Angle Class I and II malocclusions comprised 94.1\% percent of the sample. The extraction protocol of the ex patients was 4 first premolars in $67.9 \%$ and a combination of maxillary first and mandibular second premolars in $22.6 \%$. Independent $t$ tests documented a small but statistically significant difference in age at $\mathrm{T} 1$ and T3 $(P<.05$, Table I), and chi-square tests showed no significant difference in distribution of Angle classification between the ex and the nonex patients. However, women comprised $39.2 \%$ of the ex patients and $64.2 \%$ of the nonex patients $(P<.05$, chi square test).

Independent $t$ tests showed no significant difference in age $(P>.05)$, and chi-square tests showed no significant difference in distribution of Angle classification $(P>.05)$ between the selected and the excluded patients. However, women constituted $56 \%$ and $67 \%$ of the selected and excluded patients, and extraction was 
Table I. Ages before (T1) and after (T2) treatment and at least 10 years postretention (T3) at radiographic examinations of patients treated nonextraction (nonex) and with extraction of four premolars (ex)

\begin{tabular}{lccc}
\hline & $\begin{array}{c}\text { Nonex }(n=51) \\
\text { Mean } \pm S D\end{array}$ & $\begin{array}{c}\text { Ex }(n=106) \\
\text { Mean } \pm S D\end{array}$ & $P$ \\
\hline $\mathrm{T} 1$ & $11.8 \pm 1.9$ & $12.6 \pm 1.6$ & $<.05$ \\
$\mathrm{~T} 2$ & $15.0 \pm 1.9$ & $15.4 \pm 1.9$ & NS \\
$\mathrm{T} 3$ & $29.2 \pm 3.6$ & $30.6 \pm 4.7$ & $<.05$ \\
\hline
\end{tabular}

$N S$, not significant

performed in $66 \%$ and $56 \%$ of the selected and excluded extraction patients, respectively $(P<.05$, chisquare test).

Third molar impaction was defined as incomplete eruption at T2 or T3 because of inclined position relative to the second molar or the ascending ramus, or lack of space (Fig 2), with radiographic evidence of apical closure. Third molar eruption was defined as the presence of the third molars in full occlusion at $\mathrm{T} 2$ or T3.

Upper molar movement (U-MM) and lower molar movement (L-MM) were measured to the nearest 0.5 $\mathrm{mm}$ along the averaged occlusal plane on the superimposed images of the $\mathrm{T} 1$ and $\mathrm{T} 2$ cephalograms with a digital caliper (Fred V. Fowler Co, Newton, Mass). Maxillary superimposition was performed according to Doppel et al, ${ }^{23}$ and mandibular superimposition according to Björk. ${ }^{24}$

The upper (U-ES) and lower (L-ES) eruption spaces were measured on the T2 cephalograms (Fig 3). U-ES was defined as the distance from the pterygoid vertical to the distal surface of the maxillary first molar crown along the occlusal plane ${ }^{25}$ (Fig 3). L-ES was defined as the distance from Ricketts' $\mathrm{Xi}$ point ${ }^{25-27}$ or from the anterior border of the ramus $(\mathrm{R})^{4,27}$ to the distal surface of the mandibular second molar crown along the occlusal plane (Fig 3). Subjects with incomplete eruption of the mandibular second molars were not measured.

The reproducibility of the measurements was assessed by statistically analyzing the difference between double measurements taken at least 1 week apart on 10 randomly selected patients. The error was calculated from the equation

$$
\mathrm{S}_{\mathrm{x}}=\sqrt{\frac{\sum \mathrm{D}^{2}}{2 \mathrm{~N}}}
$$

where $D$ is the difference between duplicate measurements and $N$ is the number of double measurements. ${ }^{28}$
The errors were $0.44 \mathrm{~mm}$ for U-MM, $0.50 \mathrm{~mm}$ for L-MM, $0.76 \mathrm{~mm}$ for U-ES, $0.46 \mathrm{~mm}$ for L-ES(Xi), and $1.12 \mathrm{~mm}$ for L-ES(R).

A proposed total impaction score, defined as the number of impacted third molars in both arches divided by the number of third molars evaluated, was made for each of the 157 patients in the sample. Similarly, proposed maxillary impaction scores were made for the 132 patients who could be evaluated in the maxilla, and proposed mandibular impaction scores were made for the 134 patients who could be evaluated in the mandible. Separate sample means were calculated for the ex and nonex patients, and independent $t$ tests were used to test for possible significances. In addition, separate sample means of U-ES, L-ES(Xi), and L-ES(R) at T2 and of U-MM and L-MM from T1 to T2 were calculated for the ex and nonex patients, for the patients with impaction and eruption, and for the subgroups of ex and nonex patients with impaction and eruption. For these analyses, patients with impaction on 1 side and eruption on the other were included in the group of patients with impaction. Independent $t$ tests were used to test for possible significant differences.

\section{RESULTS}

The total impaction score $(P<.01)$ and the impaction scores for the maxilla $(P<.01)$ and the mandible $(P<.05$, Table II) were higher for the nonex than the ex patients. Similarly, the nonex patients had a higher proportion of impacted maxillary and mandibular third molars (Table III).

Mean U-MM was $2.2 \mathrm{~mm}$ more mesial and mean L-MM was $1.8 \mathrm{~mm}$ more mesial in the ex than in the nonex patients $(P<.01$, Table IV). Also, mean U-MM was $1.8 \mathrm{~mm}$ more mesial $(P<.01)$ in the patients with eruption than in those with impaction of the respective third molars, but no difference could be detected in mean L-MM (Table IV). No differences in molar movement (MM) were found between the subgroups of ex patients with impaction and those with eruption, or between the subgroups of nonex patients with impaction and those with eruption $(P<.05)$. The variation in $\mathrm{MM}$ was considerable, with U-MM ranging from -0.7 to $8.0 \mathrm{~mm}$ and L-MM from -1.5 to $8.3 \mathrm{~mm}$ in the ex patients; U-MM ranged from -2.7 to $5.2 \mathrm{~mm}$ and L-MM from -2.9 to $3.5 \mathrm{~mm}$ in the nonex patients.

Mean U-ES was $3.0 \mathrm{~mm}$ larger in the ex than in the nonex patients $(P<.01)$ and $1.6 \mathrm{~mm}$ larger in the patients with eruption than in those with impaction of the maxillary third molars $(P<.05$, Table V). Of the 114 patients with U-ES less than $25 \mathrm{~mm}, 79(69.3 \%)$ experienced eruption, and 2 of the 5 patients with U-ES less than $14 \mathrm{~mm}$ experienced eruption. A total of 17 

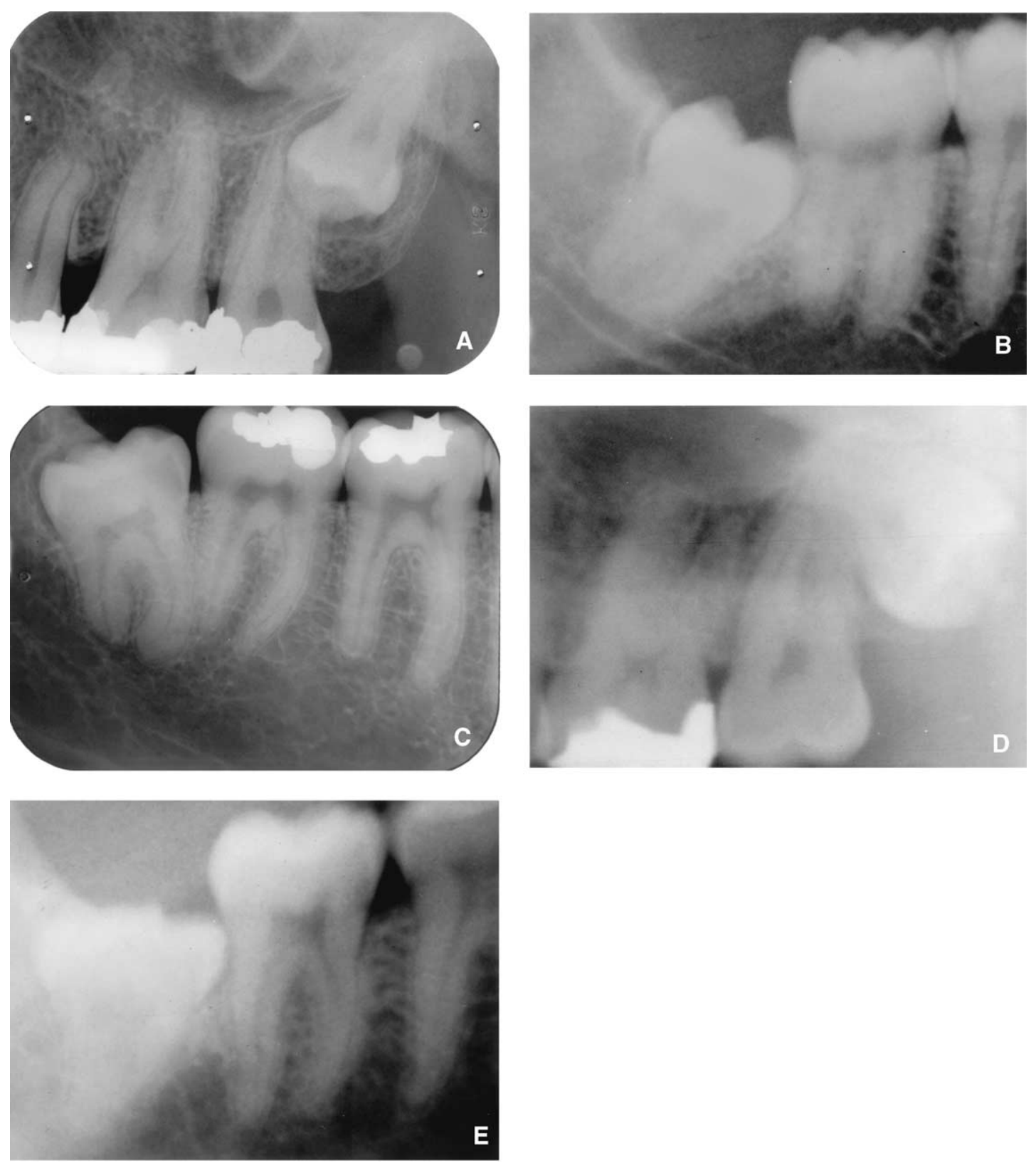

Fig 2. Periapical and sections of panoramic radiographs of patients in our sample: $\mathbf{A}$, at 33 years 9 months, illustrating mesial impaction of maxillary third molar; $\mathbf{B}$, at 29 years 2 months, illustrating mesial impaction of mandibular third molar; $\mathbf{C}$, at 30 years 1 month, illustrating distal impaction of mandibular third molar; $\mathbf{D}$, at 39 years 5 months, illustrating distal impaction of maxillary third molar; and $\mathbf{E}$, at 29 years 6 months, illustrating vertical impaction of mandibular third molar.

(20.7\%) of the 82 patients with U-ES greater than or equal to $18 \mathrm{~mm}$ experienced impaction. The smallest U-ES associated with eruption was $13.0 \mathrm{~mm}$, and the largest U-ES associated with impaction was $24.0 \mathrm{~mm}$.

L-ES(Xi) and L-ES(R) were 2.6 and $1.8 \mathrm{~mm}$ larger in the ex than in the nonex patients, and 2.7 and $1.9 \mathrm{~mm}$ larger in the patients with eruption than in those with impaction of the mandibular third molars $(P<.01$, Table V). A total of $56(64.4 \%)$ of the 87 patients with L-ES(Xi) less than $23 \mathrm{~mm}$ and $12(42.9 \%)$ of the 28 patients with L-ES(Xi) less than $19 \mathrm{~mm}$ experienced eruption of the mandibular third molars. Of the 3 patients with L-ES(Xi) greater than or equal to $28 \mathrm{~mm}$, 1 experienced impaction. The smallest value associated 


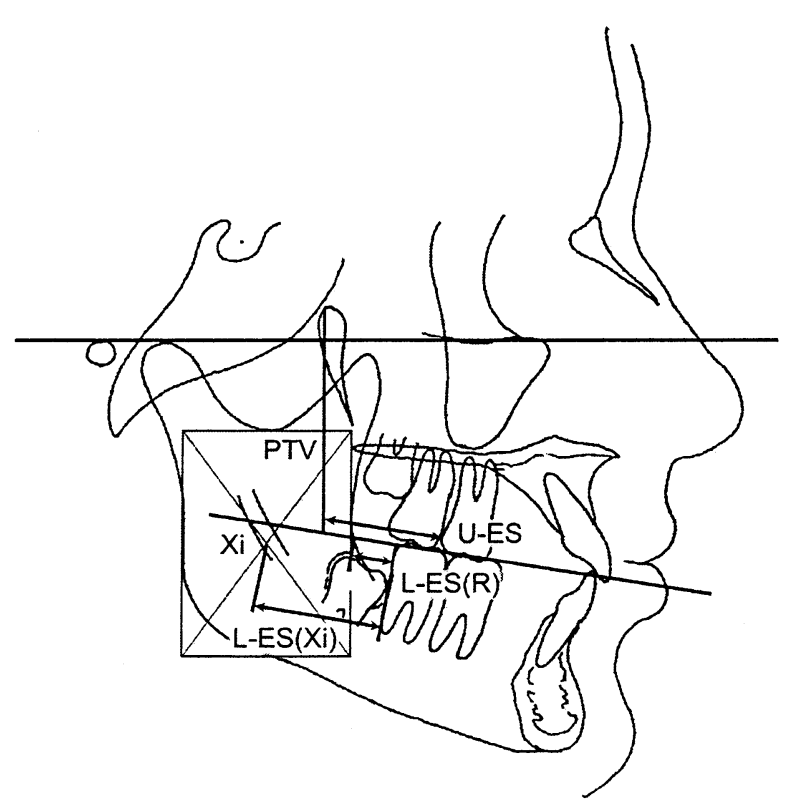

Fig 3. Cephalometric tracing indicating measurement of upper eruption space (U-ES) from projection of distal contact point of maxillary first molar on occlusal plane to intersection of pterygoid vertical (PTV) and occlusal plane, and lower eruption space (L-ES) measured from distal contact point of mandibular second molar to Ricketts' Xi point (Xi) and anterior border of ramus (R) along occlusal plane.

Table II. Total impaction score and impaction scores in maxilla and mandible of patients treated nonextraction (nonex) and with extraction of four premolars (ex)

\begin{tabular}{lccc}
\hline & $\begin{array}{c}\text { Maxilla } \\
\text { Mean } \pm S D(n)\end{array}$ & $\begin{array}{c}\text { Mandible } \\
\text { Mean } \pm S D(n)\end{array}$ & $\begin{array}{c}\text { Total } \\
\text { Mean } \pm S D(n)\end{array}$ \\
\hline Nonex & $0.48 \pm 0.50(41)$ & $0.45 \pm 0.49(38)$ & $0.48 \pm 0.48(51)$ \\
Ex & $0.18 \pm 0.38(91)^{* * *}$ & $0.22 \pm 0.40(96)^{*}$ & $0.23 \pm 0.40(106)^{* *}$ \\
\hline$* P<.05 ; * * P<.01$. & &
\end{tabular}

with eruption was $12.0 \mathrm{~mm}$, and the largest value associated with impaction was $24.5 \mathrm{~mm}$. Also, 46 $(60.5 \%)$ of the 76 patients with L-ES(R) less than or equal to $5.0 \mathrm{~mm}$ and $29(55.8 \%)$ of the 52 patients with L-ES(R) less than or equal to $3.5 \mathrm{~mm}$ experienced eruption. The smallest value associated with eruption was $-0.5 \mathrm{~mm}$, and the largest value associated with impaction was $9.0 \mathrm{~mm}$.

\section{DISCUSSION}

We confirmed the findings of Faubion ${ }^{16}$ and Kaplan ${ }^{17}$ that impaction of the mandibular third molars
Table III. Frequency of impacted and erupted third molars in maxilla and mandible of 51 patients treated nonextraction (nonex) and 106 patients treated with extraction of 4 premolars (ex)

\begin{tabular}{lccllr}
\hline & \multicolumn{2}{c}{ Maxilla } & & \multicolumn{2}{c}{ Mandible } \\
\cline { 2 - 3 } & $\begin{array}{c}\text { Impaction } \\
N(\%)\end{array}$ & $\begin{array}{c}\text { Eruption } \\
N(\%)\end{array}$ & & $\begin{array}{c}\text { Impaction } \\
N(\%)\end{array}$ & $\begin{array}{c}\text { Eruption } \\
N(\%)\end{array}$ \\
\hline Nonex & $36(50)$ & $36(50)$ & & $26(40)$ & $39(60)$ \\
Ex & $26(16)$ & $141(84)$ & & $38(22)$ & $138(78)$ \\
\hline
\end{tabular}

occurs about twice as often in nonex patients than in ex patients. Cephalometric growth studies suggest 2 important mechanisms for development of the retromolar space in the mandible: resorption at the anterior border of the ascending ramus ${ }^{4-7}$ and anterior migration of the posterior teeth during the functional phase of tooth eruption. ${ }^{4,5}$ Both might depend more on the amount and direction of condylar growth than on the presence of the third molars. The amount of periosteal apposition on the maxillary tuberosities could be more compensatory, reflecting the size and number of the maxillary posterior teeth. Accordingly, mesial movement of the molars during closure of the extraction site could have a larger effect on third molar impaction in the mandible than in the maxilla. However, we suggest that this might not be the case. Our data clearly indicate that the difference in impaction rate of the third molars between ex and nonex patients is similar in both arches.

A frequent argument for premolar extraction in borderline cases has been that the procedure might be considered a substitution for third molar extraction. However, our results suggest that this assumption is false in every fifth case (Tables II and III). It might be prudent to inform patients and their parents that premolar extraction therapy often involves the removal of 8 teeth.

Our results indicate that third molar impaction might be a smaller problem after nonextraction therapy than previously suggested. ${ }^{12,16,18,19}$ Dierkes $^{12}$ and Faubion ${ }^{16}$ concluded that only $15 \%$ of mandibular third molars erupted in good position after nonextraction therapy. Similarly, Richardson ${ }^{18}$ found that, in nonextraction patients, as many as $56 \%$ of the mandibular third molars were either impacted or had problems that needed surgical treatment. However, the samples in the above studies were rather small and might not have represented the general population. In contrast, the 157 subjects in our sample represented every case from a large patient pool that allowed accurate diagnosis of impaction versus eruption of the third molars. In addition, statistical tests ensured that the selected cases 
Table IV. Upper (U-MM) and lower (L-MM) molar movement of patients treated nonextraction (nonex) and with extraction of 4 premolars (ex) and with impaction and eruption of third molars

\begin{tabular}{lcccc}
\hline & Nonex & Ex & Impaction & Eruption \\
& Mean $\pm S D(n)$ & Mean $\pm S D(n)$ & Mean $\pm S D(n)$ & Mean $\pm S D(n)$ \\
\hline U-MM & $2.1 \pm 3.3(41)$ & $4.3 \pm 2.5(91)^{*}$ & $2.3 \pm 3.0(37)$ & $4.1 \pm 2.8(95)^{*}$ \\
L-MM & $2.3 \pm 3.2(38)$ & $4.1 \pm 2.2(96)^{*}$ & $3.1 \pm 2.8(42)$ & $3.8 \pm 2.6(92) \mathrm{NS}$ \\
\hline
\end{tabular}

$* P<.01 ; \mathrm{NS}$, not significant.

Table V. Upper (U-ES) and lower (L-ES) eruption space of patients treated nonextraction (nonex) and with extraction of 4 premolars (ex) and with impaction and eruption of the third molars

\begin{tabular}{lccrr}
\hline & Nonex & Ex & Impaction & Eruption \\
& Mean $\pm S D(n)$ & Mean $\pm S D(n)$ & Mean $\pm S D(n)$ & Mean $\pm S D(n)$ \\
\hline U-ES & $16.2 \pm 3.5(41)$ & $19.2 \pm 3.9(91)^{* *}$ & $17.1 \pm 3.6(37)$ & $18.7 \pm 4.2(95)^{*}$ \\
L-ES(Xi) & $18.4 \pm 4.8(38)$ & $21.0 \pm 4.3(96)^{* *}$ & $18.4 \pm 4.3(42)$ & $21.1 \pm 4.5(92)^{* *}$ \\
L-ES(R) & $3.7 \pm 3.3(38)$ & $5.5 \pm 3.0(96)^{* *}$ & $3.6 \pm 3.1(42)$ & $5.5 \pm 3.0(92)^{* *}$ \\
\hline
\end{tabular}

$* P<.05 ; * * P<.01$.

$X i$, Ricketts' Xi point; R, anterior border of ramus.

were similar to those that were excluded because of insufficient records. Finally, the patients in the large background pool were originally selected at random. Our sample can be considered representative of the general population of orthodontic patients.

Another problem with the previous studies was that subjects less than 18 years old were included in the samples, ${ }^{12,16,18,19}$ and most were less than 20 years old. During the screening process, we found that eruption during the final stages of root development of third molars that appear to become impacted (Fig 1) is by no means unusual. This finding suggests a risk of overdiagnosis in the previous studies. ${ }^{12,16,18,19}$ The average age of our sample was 30.2 years at T3, with a range from 22.2 years to 45.3 years (Table I), and all third molar roots showed radiographic evidence of apical closure at examination.

Although our study design precludes conclusions about cause-and-effect relationships, the results strongly suggest that the increased potential for mesial molar movement during extraction site closure, with concomitant increase in retromolar space, might be the major reason for the intergroup difference in third molar impaction. However, we could detect no difference in L-MM between patients with eruption and impaction of the mandibular third molars. Also, when evaluating the subgroups of ex and nonex patients separately, we detected no differences in MM in either arch between patients with and without third molar impaction. A similar finding has been reported in the mandibular arch in a previous study, ${ }^{17}$ suggesting that other variables could be equally important for the development of sufficient eruption space for the third molars. We also found large individual variations in the amount of MM during active appliance therapy (Table IV) and in the size of the eruption spaces at appliance removal (Table V). Such variation is well documented in the mandible. ${ }^{12-14,17}$ In ex cases, part of the explanation might be variation in the amount of canine retraction because of pretreatment differences in irregularity and in the labiolingual position of the incisors, and to mechanical variation during residual space closure. However, our results suggest that the variation is equally large in nonex cases, and as large in the maxilla as in the mandible.

Several studies have failed to use statistics when evaluating the effect of premolar extraction on impaction of the mandibular third molars. ${ }^{16-19}$ Also, it has been common to compare the number of quadrants with impaction versus eruption between groups of ex and nonex patients. ${ }^{12,16-18,20}$ However, these analyses might be biased if the tendency for eruption on the right and left sides in each patient is correlated. To overcome that potential problem, we have proposed the use of an impaction score when testing for possible intergroup significances.

It has been suggested that the size of the maxillary eruption space at appliance removal is a valid predictor for whether the third molars will erupt. ${ }^{25-27}$ One article states that at least $18 \mathrm{~mm}$ is required from the distal of the first molars to the pterygoid vertical when measured along the occlusal plane, and that the prognosis for eruption is very poor if the distance is less than 14 mm. ${ }^{25}$ However, about $20 \%$ of the patients in our 
sample experienced impaction despite a distance equal to or greater than $18 \mathrm{~mm}$, and the third molars erupted successfully in 2 of the 5 patients with a distance less than $14 \mathrm{~mm}$, calling into question the clinical significance of those dimensions as predictors for eruption and impaction. We also found that about $70 \%$ of the maxillary third molars erupted in subjects with eruption spaces smaller than $25 \mathrm{~mm}$, in contrast to only $10 \%$ as documented in a previous study. ${ }^{29}$ Part of the discrepancy can be explained because we measured eruption space at an average age of about 15 years (Table I) rather than in adults, ${ }^{29}$ without adjusting for possible growth increments. Another explanation might be that the sample was small in the other study ${ }^{29}$ and did not necessarily represent the general population.

More than $60 \%$ of the patients in our sample with a distance of $23 \mathrm{~mm}$ or less from the distal of the mandibular second molar to Ricketts' point $\mathrm{Xi}$ at the end of active treatment experienced eruption of the mandibular third molars. The mandibular retromolar space can increase about $2 \mathrm{~mm}$ from age 15 to adulthood. ${ }^{30}$ Assuming that the increase in retromolar space implies a similar increase to point $\mathrm{Xi}$, we could not confirm that the chance of eruption is nil when the predicted adult distance is less than $25 \mathrm{~mm} .{ }^{27}$ Neither could we confirm that the chance of mandibular third molar impaction is about $85 \%$ when the predicted adult distance is less than $21 \mathrm{~mm},{ }^{25}$ because more than $40 \%$ of the patients in our sample with less than $19 \mathrm{~mm}$ from the distal of the mandibular second molar to $\mathrm{Xi}$ at the end of active treatment experienced eruption of the mandibular third molars.

Previous research suggests that the probability of mandibular third molar eruption is directly related to the proportion of the third molar in front of the anterior border of the ramus before eruption. ${ }^{25-27}$ The average width of the mandibular third molar is $10.5 \mathrm{~mm},{ }^{31}$ which probably corresponds to about $11 \mathrm{~mm}$ on the lateral cephalometric image. Our findings - that as many as $60 \%$ of the subjects with a distance from the anterior border of the ramus to the distal of the second molars of $5 \mathrm{~mm}$ or less and as many as $55 \%$ of those with a distance of $3.5 \mathrm{~mm}$ or less experienced eruption-contradict those results. Our findings suggest that the size of the third molar eruption space associated with a high risk of impaction might be smaller than previously suggested.

\section{CONCLUSIONS}

Our results suggest a clinically significant reduction in the rate of impaction of maxillary and mandibular third molars in ex patients compared with nonex patients. The mechanism might be that premolar ex- traction therapy is associated with an increase in the amount of mesial movement of the maxillary and mandibular molars and an increase in the eruption space for the third molars. Our findings also suggest that the size of the third molar eruption space associated with a high risk of impaction might be smaller than previously suggested.

\section{REFERENCES}

1. Dachi SF, Howell FV. A survey of 3874 routine full-mouth radiographs. II. A study of impacted teeth. Oral Surg Oral Med Oral Pathol 1961;14:1165-9.

2. Bishara SE, Andreasen G. Third molars: a review. Am J Orthod 1983;83:131-7.

3. Grover PS, Lorton L. The incidence of unerupted permanent teeth and related clinical cases. Oral Surg Oral Med Oral Pathol 1985;59:420-5.

4. Björk A, Jensen E, Palling M. Mandibular growth and third molar impaction. Acta Odont Scand 1956;14:231-71.

5. Björk A. Variations in the growth pattern of the human mandible: longitudinal radiographic study by the implant method. J Dent Res (Suppl 1) 1963;42:400-11.

6. Alling CC III, Alling RD. Indications for management of impacted teeth. In: Alling CC III, Helfrick JF, Alling RD, editors. Impacted teeth. Philadelphia: W. B. Saunders; 1993. p. 46-9.

7. Silling G. Development and eruption of the mandibular third molar and its response to orthodontic therapy. Angle Orthod 1973;43:271-8.

8. Begg PR. Stone Age man's dentition. Am J Orthod 1954;40:298$312,373-83,517-31$

9. Murphy TR. Reduction of the dental arch by approximal attrition. Br Dent J 1964;116:483-8.

10. Cavanaugh JJ. Third molar changes following second molar extractions. Angle Orthod 1985;55:70-6.

11. Gooris CGM, Årtun J, Joondeph DR. Eruption of mandibular third molars after second molar extractions: a radiographic study. Am J Orthod Dentofacial Orthop 1990;98:161-7.

12. Dierkes DD. An investigation of the mandibular third molars in orthodontic cases. Angle Orthod 1975;45:207-12.

13. Graber TM, Kaineg TF. The mandibular third molar: its predictive status and role in lower incisor crowding. Proc Finn Dent Soc 1981;77:37-44.

14. Richardson ME. The effect of mandibular first premolar extraction on third molar space. Angle Orthod 1989;59:291-4.

15. Ricketts RM. A principle of arcial growth of the mandible. Angle Orthod 1972;42:368-86.

16. Faubion BH. Effect of extraction of premolars on eruption of mandibular third molars. J Am Dent Assoc 1968;76:316-20.

17. Kaplan RG. Some factors related to mandibular third molar impaction. Angle Orthod 1975;45:153-8.

18. Richardson ME. The development of third molar impaction. $\mathrm{Br} \mathbf{J}$ Orthod 1975;2:231-4.

19. Richardson ME. The relative effects of the extraction of various teeth on the development of mandibular third molars. Trans Eur Orthod Soc 1976;79-85.

20. Haavikko K, Altonen M, Mattila K. Predicting angulational development and eruption of the lower third molar. Angle Orthod 1978;48:39-48.

21. Proffit WR, Fields HW. Early stages of development. In: Proffit WR, Fields HW, editors. Contemporary orthodontics. 2nd ed. St. Louis: Mosby Year Book; 1993. p. 56-86. 
22. Ash MM Jr. Development and eruption of the teeth. In: Ash MM Jr, editor. Wheeler's dental anatomy, physiology and occlusion. 7th ed. Philadelphia: WB Saunders; 1993. p. 24-45.

23. Doppel DM, Damon WM, Joondeph DR, Little RM. An investigation of maxillary superimposition techniques using metallic implants. Am J Orthod Dentofacial Orthop 1994;105:161-8.

24. Björk A. Prediction of mandibular growth rotation. Am J Orthod 1969;55:585-99.

25. Schulhof RJ. Third molars and orthodontic diagnosis. J Clin Orthod 1976;10:272-81.

26. Ricketts RM, Turley P, Chaconas S, Schulhof RJ. Third molar enucleation: diagnosis and technique. J Calif Dent Assoc 1976; 4:52-7.

27. Ricketts RM. Studies leading to the practice of abortion of lower third molars. Dent Clin North Am 1979;23:393-411.
28. Dahlberg G. Statistical methods for medical and biological students. London: George Allen and Unwin Ltd; 1940. p. 122-32.

29. Ganss C, Hochban W, Kielbassa AM, Umstadt BE. Prognosis of third molar eruption. Oral Surg Oral Med Oral Pathol 1993;76: 688-93.

30. Ledyard BC. A study of the mandibular third molar area. Am J Orthod 1953;39:366-73.

31. Ash MM Jr. Mandibular second molar. In: Ash MM Jr, editor. Wheeler's dental anatomy, physiology and occlusion. 7th ed. Philadelphia: W. B. Saunders; 1993. p. 291-9.

32. Olive R, Basford K. Reliability and validity of lower third molar space-assessment techniques. Am J Orthod 1981;79:45-53.

33. Forsberg CM, Vingren B, Wesslèn U. Mandibular third molar eruption in relation to available space as assessed on lateral cephalograms. Swed Dent J 1989;13:23-31.

\section{BOUND VOLUMES AVAILABLE TO SUBSCRIBERS}

Bound volumes of the American Journal of Orthodontics and Dentofacial Orthopedics are available to subscribers (only) for the 2003 issues from the Publisher, at a cost of $\$ 96.00$ (\$115.56 Canada and \$108.00 international) for Vol. 123 (January-June) and Vol. 124 (July-December). Shipping charges are included. Each bound volume contains subject and author indexes, and all advertising is removed. The binding is durable buckram, with the journal name, volume number, and year stamped in gold on the spine. Payment must accompany all orders. Contact Mosby, Subscription Customer Service, 6277 Sea Harbor Dr, Orlando, FL 32887; phone 800-654-2452 or 407-345-4000.

Subscriptions must be in force to qualify. Bound volumes are not available in place of a regular Journal subscription. 